23rd, and the patient was discharged on Jan. 4th, 1894, apparently well. About a week after her discharge she was attended outside the infirmary, and complained of pain and tenderness in the left iliac region; a small growth was there felt, which grew with such rapidity that it almost filled the abdominal cavity within a month. D'stinct lobulated masses could be felt, and the peritoneal pain was intense. She died from exhaustion on Feb. 10 $\mathrm{h}$.

CASE 2. Extra-uterine foetation.-A woman aged twentyeight years was admitted into the Burton-on-Trent Infirmary on June 13th, 1894, in a state of collapse. There was a history of three months' irregular menstru ztion with pain and swelling in the left ovarian region; the patient had become suddenly collapsed a few hours before admission. On opening the abdomen the left Fallopian tube was found to be distended by a tamour which had ruptured into the peritoneal cavity and was bleeding freely; there was a large amount of blood in the abdomen. The left ovary and tube were removed, the peritoneal cavity washed out, and the incision in the abdominal wall closed. The patient made a good recorery.

Remarks by Mr. Mason. - The tumour removed in Case 1 was sarcomatous in structure, and contained not orly several fair-sjzed cysts, but also an unmistakable abscess with rugged walls. This was evidently on the point of bursting when the operation was performed. This is the second occasion on which I have found a similar cordition to exist, my other patient being an elderly woman with a large tumour which, on removal, was found to be solid except for two large abscesses at some distance apart. In this case the tumour was universally adherent and had no pedicle, the abdominal-wall wound healed by flrst intention, but the patiert became suddenly ill at the end of a fortnight and died from the effects of frcal extravasation, probably due to the injury of the kowel during the separation of the adbesions.

ROYAL VICTORIA HOSPITAL, NETLEY.

BONY ANKYLOSIS OF HIP-JOIST; MALPOSITION ; OSTEOTOMY; RECOVERY WITH USEFUL LIMB ; REMARKS.

(Under the care of Surgeon-Major H. R. WHITEHEAD, Assistant Professor, Military Surgery.)

THE operation described as the subcutaneous section of the femur below the trochanters was first performed by Mr. Gant in December, 1872, and we published an account of the operation in THE LANCET of the 21st of that month. There is little doubt that it is the operation which is best adapted for the correction of bony ankylosis of the femur in a bad position alter disease of the hip-joint of a tuberculous natare. The principles of the operation described below were the same as guide the surgeon in Gant's operation; but there are cne or two details which differ. For instance, Gant ${ }^{1}$ writes that the knife was "passed down to and orer the fewur, co as to make a transverse line across the bone; then the knife is withdra wn and, still keeping the thumb in position not to lose the track of the narrow subcutaneous incision, a thin, narrow-bladed saw is entered at the same point and passed along the track of the wound across the femur, which is then readily sawn through.

Macewen's osteotome is such a useful implement that many surgeons now prefer it to the saw.

A trumpeter in the R syal Artillery, eighteen years of age, was invalided home from Kigypt, and was admitted to the Royal Victoria Hospital, $N \in t l \in \mathrm{y}$, in November, 1893, suffering from hip joint disesse of nixe months' duration. He enlisted at the age of fourteen years, ard had enjoyed good health till March, 1893, when he bezan to feel acute pain in the right hip-joint, which was much increased by any movement or by pressure on the sole of the foot, and be was urable to walk. There was no history of a fall or any injury to account for the origin of the disease. He was admitted icto hospital at Cairo. An abicess formed and pointed anteriorly; tbis was opened, and discharged for some months, ultimately healing in February, 1894 Fur some months he suffered from a hectic temperature. Extersion was applied to the leg in Jare, 1893, which diminished the "starting pain" in the joint. On his admission to the Royal Victoria Hospital, Netley, in November, 1893, the patiert was in a very feeble and emaciated condition. He had bedsores on bis bank, and a sinus existed in the right groin, discharging a gl tiry fluid; the track, however, did not lead down to dead bone. The right thigh was flexed on the abdomen, the knee was semiflexed, the foot was $\in$ verted, and the leg and thigh rotated outwards. Lordosis was present even when no attempt was made to straighten the limb, and this condition was greatly exag. gerated on any attempt being made to do so. As soon as the bedsores bad healed sufficiently extension was applied, bat failed to bring the limb into a better position. There was hardly any pain about the hip, and the discharge lessened daily, till in February the sinus had completely healed. No movement could be obtained in the hipjoint. In April, as all pain had ceased and the sinus bad completely healed, the efforts to improve the position of the leg by extension having a'so failed, it was decided to place the patient under the influerce of an aræ3thetic, to decide definitely the nature of the ankylosis, and if possible to straighten the limb. After complete anæsthesia had been projuced it was found that absolute'y no movement could be procured in the hip.j int. The knee, which was semiflexed, was, however, straightened. The next day the hip.joint was entirely free from pain, and no doubt now existed that the ankylosis was of a true bony nature. It was, therefore, decided to divide the femur in its upper part, with the view of giving the patient a straight and useful limb. On May 1st, after the limb had been carefully prepared by washing and the skin rendered aseptic, the patient was placed under the inflaence of chloroform. He was then plared on his left side and the right thigh laid on and supported by a large sand pillow. An incision was made in the line of the shaft of the femur, commencing three inches below the tip of the great trochanter, about an inch and a half long, and carried $d o w n$ to the bone. The periosteum was divided and the soft parts were held aside by retractors. A Macewen's osteotome was introduced and the shaft of the femur was divided just below the small trochanter, as suggested by Gant. On attempting to straighten the limb some bands of fascia on the anterior aspect of the limb, attached to the anterior superior iliac spice, were found to be tense, and were divided subcutaneously by a tenotome; the limb could then be brought into a straight and good position. The operation wound was closed by two silver sutures and a continuous hors ehair suture, and the part was dressed with an aseptic gauze dressing. An interrup ed lorg splint was applied to the side, and extension by a 7-1b. weight was also employed. The patient made a complete recovery after the operation. His temperature did not rise above $99.2^{\circ} \mathrm{F}$.; it reached this on the evening of the day of operal $i$ in and afterwards remained uninterruptedly normal. The wound was dressed on the sixth and twentieth days, and healed at once. Seven weeks alter the operation the long splint and extension wese removed; the leg and thigh were in excellent position, and complete consolidation of the shaft of the femur had taken plac $\Rightarrow$. Oa measurement the right $l=g$ was fourd to be $a$ shade under balf an itch shorter than the left. Excellent movement existed in the right knee-joint. A Thomas's hipsplint was applied for a few days and the patient allowed to get about. He gained strength rapidly, and at the end of nine weeks was able to walk with comfort with the aid of a stick and a slightly raised sole. The pelvis allowed of much motion. He was discharged from hospital on July $9 \mathrm{~h}$, ten weeks after the operation, and although unfit for military service he had a very useful leg and was quite capable of earning his living in civil life.

Remarks by Sargeon-Major WhITEHeAD.-In this case the choice of operation seemed the culy difficult y. Adams' operation for divisicn of the neck of the bore did not seem applicable in this case, as suppuration had evidently taken place in the joint, and probably absorption of the neck of the bone had taken ulace to some extent. Barton's method of divicing the bone by a chain saw was thought of, but in exceriments on the bones of animals the saw icvariably jammed and kecame useless. Macenen's osteotome stems in evesy respect a very suitable and satisfactory instrument. Some litule trouble was caused in gettirg the metal to the rjght temper to aroid chipping of the cdge, and as a matter of $f_{i}$ ct a piece of the edge did clip off at the operation; it was left in the bore, but it produced no discomfort.

Royal Institution.-The Friday evening metings of the members commenced on Jan 18th, when a lecture was delivered by Professor Dewar cn Phosphoresence and Photograpkic Action at the Temperature of Buiing Liquid Air. 


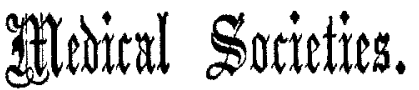

\section{MEDICAL SOCIETY OF LONDON.}

\section{Cycling and Heart Disease.}

AN ordinary meeting of this society was held on Jan. 14th, the President, Sir William Dalbr, being in the chair.

Sir BENJAMIN WARD RICHARDSON read a paper on Cycling and Heart Disease. He commenced by saying that a few months ago Dr. Petit of Paris had read a paper before the French Academy of Medicine bearing on disease and cycling, ${ }^{1}$ in which several sudden deaths from beart disease during cycling were referred to, and the possible dangers attending cycling exercise were commented upon. Sir B. W. Richardson, who had been a practical cyclist since 1877 (over sixteen years), and who had ridden with numberless riders of different ages and sexes and under the most varied conditions, ventured, therefore, to detail from his experience certain of the effects he had observed. He divided his paper into the following beads : (1) the immediate effect of the exercise on the rider; (2) the after-effects, as observed in the consulting-room, and the conditions in regard to the heart and circulation under which riding was favourable or unfavonrable; and (3) a summary of the more salient medical considerations. With regard to cycling and its effects upon the body at large, Sir B. W. Richardson said that the exercise told primarily and most distinctively on the heart, in which it differed from other exercises. In all riders at all ages it produced at once a quickened circulation, though riders themselves might not be conscious of the phenomenon. The effort might be so extreme as to cause the pulse to rise from 65 or 75 to 200 beats per minute, and although after a longer time it sobered down it was always a quickened action whic's continued so long as the rider was at work. This act of quickened movement accounted, the speaker observed, for the astounding journeys a fully trained cyclist cou!d undertake, journeys lasting two or three days and nights when the cyclist was in his prime. The same probably accounted for his endurance as against sleep, the circulation through the brain being one continued series of waves by which the molecular change of the brain occurring doring natural sleep was suspended. The sounds of the heart and the readings of the pulse were then described, and the conditions under which the heart increased in action, and sometimes underwent enlargement. He had, however, never once seen a rider embarrassed by cardiac overstrain, faintness, breathlessness, angina, or vertigo so as to be obliged to dismount. Indeed, he had known a practical rider who could climb a hill on his machine, but conld rot mount a flight of stairs on his feet without breathlessness and slight palpitation; also he had never seen a sudden death from cy cling. Under the second head Sir B. W. Richardson remarked that he had met with instances in which after some years of cycling there was evidence of cardiac disease, with general languor and inability to sustain fatigue if exercise were again tried on the machine. On the other hand, he had known examples in which even an octsgenarian had kept up the exercise in a moderate degree, apparently with benefit to the circulation, and who in one journey bad ridden from London to Bedford. In certain unstances he had seen what appeared to be benefit arising from cycling, even when there was an indication of some disease affecting the circulation. He had known good arise from it in cases of varicose veins, in examples of fatty degenerations, and unquestionably in conditions of anæmia. After discussing opposite conditions, in which excessive cycling had become a definite cause of injury to the circulation, he passed to his third head in the following summary. "First, cycling, when carried on with moderation, may, in so far as the healthy heart is concerned, be permitted or even recommended by practitioners of the healing art. Secondly, in all cases of heart disease it is not necessary to exclude cycling. It may even be uscful in certain instances where the action of the heart is feeble and where signs of fatty degeneration are found, since increased muscular exercise often improves the condition of muscle, and of no muscle more than the heart it self. Thirdly, as the action of cycling tells directly upon the motion of the berrt the effect it produces on that organ is phenomenally and unexpectedly great in regard to the work it gets out of it. Fourthly, the ultimate action of severe cycling is to increase the size of the heart, to rencer it irritable and hyper-sensitive to motion, the cycling acting upon it like a stimulant. Fifthly, the over-development of the heart under the continued overaction and extreme over-action affects in turn the arterial resilience, modifies the natural blood pressure, and favours degenerative structural change in the organs of the body generally. Sixtbly, a fact that has only been incidentally noticed in this paper is worthy of notice-namely, that in persons of timid and nervous natures ('neurotics') the fear incidental to cycling, especially in crowded thoronghfares, is often creative of disturbance and palpitation of the heart, and ought to be taken account of as a piece of preventive advice. Seventbly, in advising patients on the subject of cycling it is often more important to consider the peripheral condition of the circulation than the central. Enfeebled or worn out arteries may be more dangerous than the feeble heart, and, when connected with a heart that is over-active, are seats of danger. This same remark would, of course, apply to cases where there is local arterial injury, as in aneurysm. Eightbly, venous enlargement $s \in \mathrm{ems}$ rather to be benefited than irjured by cycling, and conditions marked by sluggish circulation through vems are often greatly relieved by the exercise. Ninthly, there are three things which are most injurious in cycling-(a) strainirg to climb hills and to meet head winds; $(b)$ excessive fatigue; and $(c)$ the process of exciting the heart and wearing it out sooner by alcoholic stimulants, and the omission of light, frequently repeated, and judiciously selected foods. Lastly, the time has arrived when practitioners of medicine everywhere should make observations for themselves that contirm or confute these observations and add to them so much more that I of necessity have omitted."

The PRESIDEXT, in tharking Sir B. WV. Richardson for his paper, referred to the influence which remarks from him exerted on the public mind, and rejoiced that from him should come words of reassurance and caution in the use of the cycle. It was apparent that cycling exerted nothing like the strain upon the heart which was entailed by other forms of athletic exercise, such as rowing or sparring.

Dr. SANSOM congratulated Sir B. WT. Richardson on having made a substantial addition to our knowledge on a subject of growing importance. A practitioner, he thought, should be something of a cyclist to be able to appreciate and advise upon the disturbances incidental to riding. He deprecated the absurd resolutions of the French Academy of Medicine with regard to the dangers of cycling, and regarded the recommendation to adopt searchirg anthropomorphic mearurements in those intending to ride as bordering upon the ridiculous. Referring to his oration on Rapid Heart, delivered before the society, he could only recall one instance in a cyclist, and he bad met with no instance of irregular heart among riders. He thought the worst form of exertion was the running to catch a train, which produced both irregularity and rapidity of heart beat. The influence of cyclirig was decidedly more in the direction of gocd than in that of evil. As a therapentic agent in the treatment of actually existing heart disease it was quite in accord with the recommendations of Professor Hirtl of Munich, who prescribed physical exercise, but he thought cycling had many advantages over climbing, which Professor Hirtl extolled. He looked upon the cycle as an im. portant hygienic and therape utic agent, ard thought it was responsible indirectly for the immense moral improvement noticeable in the track and the era of the cycle.

Dr. MACGEAGH said it was a very important point in cycling to avoid pushing against one's inclination up steep gradients. He felt the exertion much less than that of other forms of athletic exercise, and found that under it be maintained a perfectly even body weight. The chief strain, he thought, fell upon the nervous system, axd was liable at first to in. duce sleeplessuess ; this, however, soon wore cff.

Dr. RoUTH inquired as to Sir B. W. Richardson's experience of ladies cycling.

Dr. WASHINGTON ISAAC referred to Mr. Bridgman of Berkley developing heart disease while he was a cyclist and to his making the discorery himself with a binaural stethoscope.

Dr. Fletcher Litrue said that the tremulousness so often complained of formerly had diminished greatly sinee the improvement in saddles and tyres. He thought there was 